\title{
The Research of Basic Computer Teaching of Higher Vocational Based on Flipped Classroom
}

\author{
Zhijun Su \\ Zhejiang Tongji Vocational College of Science and Technology \\ Hangzhou, China 311231
}

\author{
Xiumei Jing \\ Zhejiang Tongji Vocational College of Science and \\ Technology \\ Hangzhou, China 311231
}

\author{
Changyun Wang \\ Zhejiang Tongji Vocational College of Science and \\ Technology \\ Hangzhou, China 311231
}

\begin{abstract}
Flipped classroom is a new teaching model of reversal arrangement of imparting knowledge and knowledge internalization, which plays a role in enhancing students' interest and improving their innovation ability. According to the steps of video learning before class, knowledge Internalization in class and imparting knowledge after class, the flipped classroom teaching mode is constructed in basic computer teaching of higher vocational through interaction online platform between teachers and students. At last, the paper discusses the problem which should be heeded in flipped classroom.
\end{abstract}

Keywords-flipped classroom; higher vocational education; teaching model; basic computer

\section{INTRODUCTION}

Fundamentals of computer is a public course designed for freshmen in colleges, and the course is in wide involvement of knowledge and skills, strong in practice, which plays a fundamental and leading role in training students' abilities of applying information technology. Currently a series of reforms are being done aiming at the course, to which many teachers raises teaching means and tools. However, due to restrictions of diverse factors, many colleges and universities still adopt traditional teaching modes such as disseminating knowledge in theoretical courses, instructing students' operation in practice courses and reinforcing in training courses.

Flipped classroom is a new teaching mode where traditional class teaching and after-class learning are interchanged, the traditional teaching consists of knowledge dissemination and knowledge internalization, the former is completed in class by teachers, and the latter is done by students through homework, operation and practice after class. The flipped classroom is just overturning the traditional mode, which the knowledge dissemination is achieved via teaching video after class, and the knowledge internalization is done via the assistances of teachers and students in class, which is a teaching mode on the basis of the information technology and individual involvement [1].

The students of high vocational education are poorer in learning motivation and devotion than undergraduates, traditional teaching is focused on teachers, which caused students to passively receive the knowledge and skills disseminated by teachers, ignoring the students' integration in what they have learned and influencing the students' activity, enthusiasm and creativity in learning [2]. In our opinions, the flipped classroom is a successful attempt to explore individualized teaching via technologies, which does good to improving the teaching quality. The introduction of flipped classroom to the fundamentals of computer course may change the gap between the status quo of high vocational teaching and social demands to some degree, which will play an active role in the reform and innovation of the course.

\section{FliPPED ClaSSROOM TEACHING MODE OF FUNDAMENTALS OF COMPUTER}

Though the flipped classroom contains motile teaching elements such as project-driven method, problem-solving learning, case teaching and online videos which were attempted teachers, yet it in nature is an integrated tool for active learning. According to characteristics of the fundamentals of computer course and the requirements of focusing on training students' capabilities in career in the higher vocational education, the flip classroom mode is adopted to design the teaching flow, and a whole teaching course is formed according to the pre-class video learning, inclass internal training and after-class reinforcement. And an online interactive platform is created "Fig 1", which takes teaching and learning as two aspects, and closely combines the students' pre-class preparation and after-class review, forming a solid knowledge and skills learning system.

The paper is sponsored by the research project of education management of Zhejiang water resources department, "Research on the standardization and evaluation system of online learning for water conservancy personnel". Number: (RC1647). 


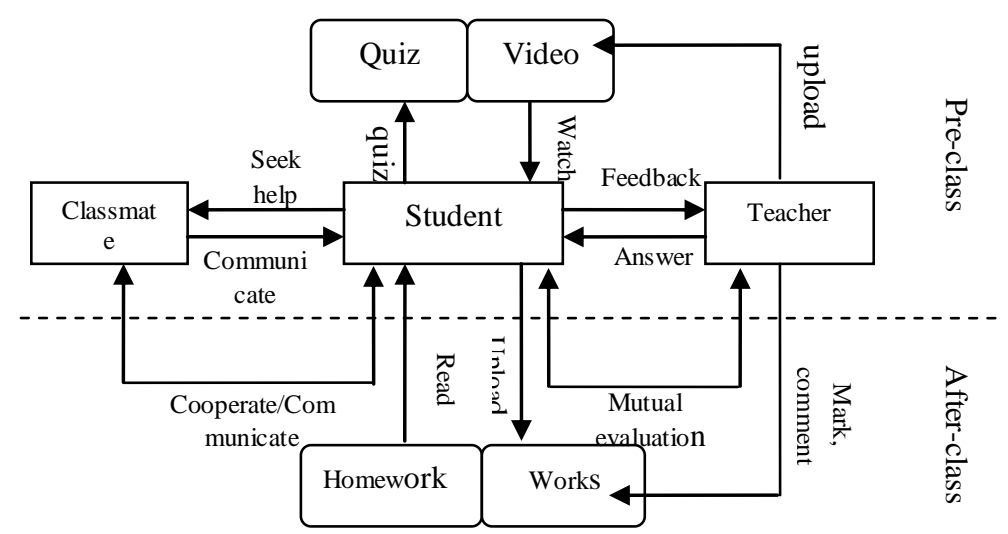

Fig. 1. Teacher-student interaction platform at flipped classroom.

\section{A. Pre-class Video Learning}

According to requirements of the flipped classroom, teachers should create and post learning videos on the online interactive platform. The fundamentals of computer course is strong in practice and wide in operation and rich in knowledge, first of all, divide all knowledge of the course into modules such as basic knowledge, Windows 7, Word 2010, Excel 2010, PPT2010 and so on. Each knowledge module is subdivided into key points.

For example, the Word knowledge module can be divided into format setting, page layout, table making; the Excel module can be divided into function formula, data processing, icons and so on. The making of teaching videos are based on knowledge points, and the teaching videos for the flipped classroom should be dapper (not more than 10 minutes in duration), stressing the theme and interpreting the key points, difficult parts and core contents. The fundamentals of computer course has many knowledge points, diverse functions and targeted, which are not complicated actually, therefore, the knowledge points can be used to divide the video teaching units for a better effect.

The video design shall follow three procedures namely introduction to concepts, purpose and function and how to achieve, before interpreting the knowledge points, teachers shall set some small problems, so that the students can watch the videos with questions and find answers therein, after playing of each video, the students should complete quizzes given by teachers, they can also talk with classmates and the quiz results will be feedback to the students online. On designing problems and quizzes, teachers have fully considered the knowledge of students, and the number of quiz questions and difficulty shall be kept fit, which shall be both challenging and answerable. The students collect some of the problems arising out of the quizzes after completion of the quizzes and take them to the classroom, and the teachers will integrate the knowledge points shown in the pre-class videos into the operable projects that the students are familiar with (as shown in "Fig. 2") and training in class [3].

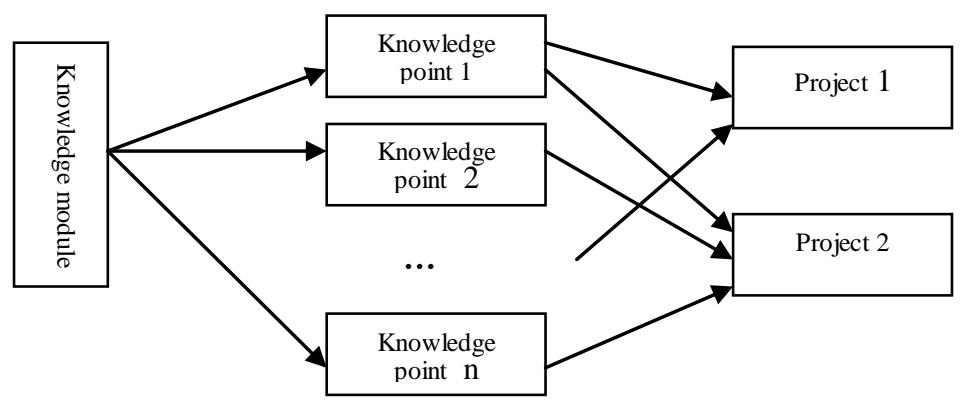

Fig. 2. Relations between knowledge module and operable projects.

\section{B. Internalized Training in Class}

Higher vocational education is paying more and more attentions to the training of students' abilities of practice, while the classroom is a main place for that and a key factor influencing the learning effect. Therefore, the class teaching is a main point that determines the effect of the whole flipped classroom. In the flipped classroom, the knowledge dissemination is transferred to the pre-class video teaching, so teachers need to integrate the knowledge in the video teaching into the projects, and reinforce the knowledge through actual training and operation, the whole class teaching is shown as in "Fig. 3". 


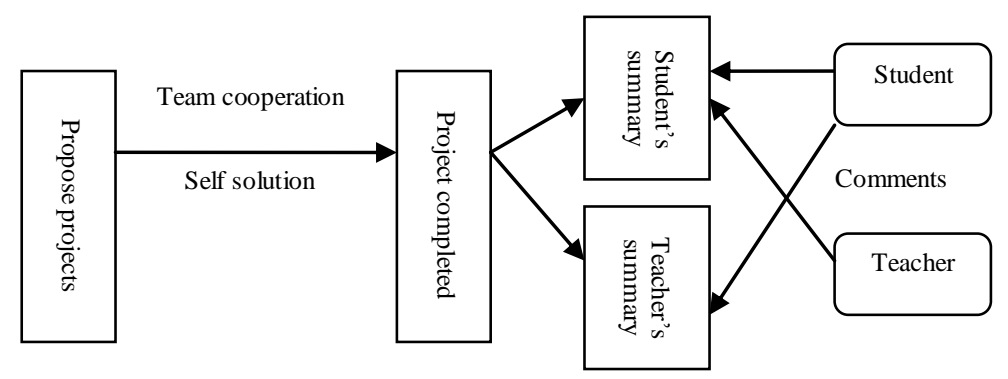

Fig. 3. Internalized training at the flipped classroom..

1) Propose projects and tasks: Before proposing projects to be completed for the class, first of all, teachers should answer the questions from the students' feedback before class, after collecting and sorting, the teachers shall set the answers method to problems, and make the best of the questions, and guide the pre-class knowledge to the actual projects. The project proposed shall be targeted, which shall contain the knowledge and skills shown in the pre-class videos be combined with life and work, for example, use Word to create resumes, fire manual for dorms and so on; use Excel to create financial statements, student society name-list statistics; use PPT to create PPT files such as campaign for student chairman, college publicity album and so on. The teachers should show the project requirements, goals, key points, difficulties as well as specific tasks, and special statements shall be made to students to prevent the interlocked errors after completion of the projects.

2) Complete projects through operation: During the teaching of fundamentals of computer, teachers should pay more attentions to training the students' abilities of independent learning and independent problem solution so as to internalize the knowledge and skills and construct a knowledge system of their own. Besides, it is still needs teamwork to complete the projects, according to the characteristics of their own, the students can be grouped, 2-3 persons per group, and the projects different in themes but similar in operation are assigned to one group for discussion, members of each group may show their opinions at any time, and the members in a group may communicate and cooperate to achieve the learning goals in class [4]. According to the difficulty of projects and workload, the teachers may decide to adopt self solution or teamwork for solution.

3) Summary and comments: The class teaching of fundamentals of computer is also a course of information sharing, through the training, students may obtain diverse experience whether successful or failing, and the experience of a student or a group can be used for others, which can be completed via summary and comments. The flipped classroom adopts a student-centered multiple summary and comments, which is to a basic request constructed by the flipped classroom, through the project works show, students or teachers may complete the summary, others watch and then make comments, which can be done through summarizing by students, self-comments by students, joint comments by teachers and students or summarizing by teachers on behalf of students, joint comments by teachers and students. Contents for comments mainly include successful experience in completing projects, shortcomings, mistakes and lessons, abilities of students in solving problems in class, teamwork and so on. Considering the comment results, the teachers shall decided how to continue the next classroom design [5].

\section{After-class Reinforcement}

After the knowledge is internalized through in-class training, it also needs the learning materials provided after class for makeup. Through the in-class interpretation and interactive discussion between teachers and students, the students, the teachers may make defects and arrange some tasks to reinforce what the students have learned in class, and each student will review the errors and innovation arising out of in-class training, besides, the teachers shall add the contents which are not or to be completed in class the afterclass tasks so as to make up the knowledge. Finally, the students will post task results on the flipped classroom platform, to which, the teachers will make summary and comments so as to complete the whole class teaching.

\section{Problems to Be KnOWN While CARR Ying OUT THE FLIPPED CLASSROOM MODE}

\section{A. How to Mobilize the Students' Enthusiasm to Learn}

Considering that the students of higher vocational education have worse habits in learning in middle schools, lack of enthusiasm in learning, besides, the fundamentals of computer course have a lot of knowledge points and all kinds of operating skills, how to integrate the knowledge and skills into the teaching videos and also attract students to active video learning requires that the teachers have to make full efforts in the video making quality, content control and compatibility, the videos shall be interactive, avoiding the direct knowledge dissemination and leaving students some spaces for thinking and making the students enjoy after-class learning; on the other hand, the students shall be supervised to learn, for example, make the online monitoring to check whether the students have watched the videos so as to assess 
the students' results, in the meantime, the classmates can supervise each other to achieve the goals.

\section{B. Adaptation of Course Contents}

As far as the fundamentals of computer course, during the flipped classroom teaching, the teaching strategies shall vary with the teaching contents. Generally in the flipped classroom, teachers will make short videos with the key points, difficulty and questioned parts in teaching, however, just some the contents suit the method. For example, the former basic computer knowledge module and the following office 2010 module pre-class videos, in-class training and after-class tasks obviously can not adopt the same model, the former can adopt the theory interpretation, concept recognition and topic tests, the latter can adopt skills interpretation, operation training, works submission and so on. In a word, teachers shall be encouraged to make independent innovation according to the characteristics of courses, all shall be advocated as long as they can mobilize students' interests and thinking and play an active role in learning.

\section{Teachers' Professional Skills, Time and Energy}

The pre-class video making, conception of projects in class or the design of after-class tasks all require teachers to contribute more time and energy, as well as higher professional level and the knowledge. When making videos before class, teachers shall guide students to participate in the video learning, highlighting the effect in vision and hearing, besides, the teaching videos shall be made diverse, avoid dull interpretation; more knowledge points shall be integrated to the in-class projects, avoid making a blunt feeling to students, in the meantime, more chances shall be offered to students for deep thinking, and the students shall be trained in independent solution of problems or teamwork. After class, the teachers shall be active to discover what the students hold questionable, check any omission and make up in time [2].

\section{CONCLUSION}

The flipped classroom is a subversive innovation to the traditional teaching mode, and as far as the fundamentals of computer course in the higher vocational education, the construction of the flipped classroom greatly enhances the students' initiative in learning, bringing chances to train their abilities of exploration, independent solution of problems, communication and teamwork. In practice, the teachers have to continue the exploration and innovation and have the flipped classroom teaching mode improved constantly.

\section{REFERENCES}

[1] Li Hailing, Deng Minjie, Liang Cunliang, Design and Application of Task -based Flipped Classroom Teaching Mode [J]. Modern Educational Technology, 2013, 23 (9):46-51.

[2] He Chaoyang, Ou Yufang, Cao Qi, Enlightenment of the Flipped Classroom Teaching Mode in the US [J]. Research in Higher Education of Engineering, 2014,2:148-151.
[3] Zeng Mingxing, et al, Research on the Flipped Classroom Teaching Mode Relative to Software Development [J]. Laboratory Research and Exploration, 2014,33 (2):203-209.

[4] Wang Hong, et al, Design of the Flipped Classroom Teaching Mode - based on typical cases at home and abroad [J]. Modern Educational Technology, 2013, 23 (8):5-9.

[5] Huang Jing, Construction of Flipped Classroom on the basis of Students' Mutual Comments [J]. China Medical Education Technology, 2014, 28 (1):13-17. 